\title{
UJI AKTIVITAS ANTIBAKTERI DARI SPONS Dictyonella funicularis DAN Phyllospongia lamellosa YANG DIAMBIL PADA PERAIRAN BUNAKEN
}

(Antibacterial activity test of sponge Dictyonella funicularis and Phyllospongia lamellosa collected from Bunaken marine waters)

\section{Angeline E. C. Ngantung ${ }^{1 *}$, Deiske A. Sumilat ${ }^{1}$, Robert A. Bara ${ }^{1}$}

1. Program Studi IImu Kelautan, Fakultas Perikanan dan IImu Kelautan, Universitas Sam Ratulangi, Manado

*e-mail : angelchristiany@gmail.com

Sponges is one of reef building marine organisms. This animal contains so many compounds that have a potential to be expended in medical field, one of them as an antibacterial. This research aims to find the antibacterial potential and make an antibacterial activity test from sponge Dictyonella funicularis and sponge Phyllospongia lamellosa from Bunaken marine waters, North Sulawesi. The result shows that the extract of sponge Dictyonella funicularis and sponge Phyllospongia lamellosa has an antibacterial activity. The extract of sponge Dictyonella funicularis has a higher antibacterial activity than the extract of sponge Phyllospongia lamellosa and also have a potential to be expended as an antibacterial medicine.

Keywords: Sponge, Dictyonella funicularis, Phyllospongia lamellosa, Antibacterial, Bunaken Marine Waters

Spons merupakan salah satu biota laut penyusun terumbu karang. Hewan laut ini diketahui mengandung senyawa-senyawa yang berpotensi untuk dikembangkan dalam bidang pengobatan, diantaranya sebagai antibakteri. Penelitian ini bertujuan untuk mengetahui potensi antibakteri dan melakukan pengujian aktivitas antibakteri dari spons Dictyonella funicularis dan Phyllospongia lamellosa yang diambil dari perairan Bunaken, Sulawesi Utara. Hasil penelitian menunjukkan bahwa ekstrak spons Dictyonella funicularis dan Phyllospongia lamellosa memiliki aktivitas antibakteri. Ekstrak spons Dictyonella funicularis menghasilkan aktivitas antibakteri yang lebih tinggi dibandingkan ekstrak spons Phyllospongia lamellosa dan memiliki potensi untuk dikembangkan sebagai obat antibakteri.

Kata kunci: Spons, Dictyonella funicularis, Phyllospongia lamellosa, Antibakteri, Perairan Bunaken

\section{PENDAHULUAN}

Indonesia merupakan negara kepulauan terbesar di dunia yang memiliki wilayah laut sangat luas dengan panjang pantai $99.093 \mathrm{~km}$ (Badan Informasi Geospasial, 2015). Hal ini berkaitan erat dengan keanekaragaman sumberdaya alam hayati laut yang tinggi, salah satunya ialah ekosistem terumbu karang. Dalam ekosistem terumbu karang hidup berbagai jenis biota laut, termasuk di dalamnya spons laut (Mokodompit et al., 2015).

Spons merupakan salah satu komponen biota penyusun terumbu karang yang penyebarannya cukup luas. Terdapat 15.000 spesies spons di seluruh dunia dan sekitar $45 \%$ senyawa bioaktif ditemukan pada spons 
(Denning, 2006). Kandungan metabolit menangkal dan menghambat bakteri patogen pengganggunya. Hal ini membuat spons menjadi salah satu hewan laut yang menarik untuk diteliti karena berpotensi besar untuk dikembangkan dalam bidang pengobatan yaitu sebagai antibakteri (Abubakar et al., 2006; Suparno, 2005).

Penelitian ini secara umum bertujuan untuk meneliti manfaat spons dalam bidang kesehatan khususnya sebagai antibakteri dan untuk menguji tingkat aktivitas antibakteri dari beberapa spons yang diambil dari perairan Bunaken, Sulawesi Utara.

\section{METODE PENELITIAN}

\section{Tempat dan Waktu Penelitian}

Pengambilan sampel dilakukan pada dua lokasi di perairan Bunaken, yaitu Tanjung Parigi dan Mamaling. Kemudian penelitian dilanjutkan di Laboratorium Riset Biomedik Fakultas Kedokteran Universitas Sam Ratulangi. Penelitian dilaksanakan dari bulan Februari sampai bulan April 2016.

\section{Prosedur Penelitian}

\section{Persiapan Sampel}

Pengambilan sampel dilakukan pada kedalaman $5 \mathrm{~m}$ - $10 \mathrm{~m}$ menggunakan alat selam. Sampel yang diambil selanjutnya dipotong kecil-kecil berbentuk kubus/dadu, direndam dalam larutan etanol 95\% dan dibawa ke Laboratorium Riset Biomedik Fakultas Kedokteran UNSRAT.

\section{Identifikasi Sampel}

Pengidentifikasian sampel spons dilakukan dengan melihat bentuk, warna, dan struktur spons. Jenis spons ditentukan dengan pencarian melalui buku Biologi Laut (Nybakken, 1988) dan situs "www.spongeguide.com".

\section{Sterilisasi Peralatan dan Lingkungan Kerja}

Alat-alat gelas yang digunakan terlebih dahulu dicuci bersih, sekunder dari spons diketahui mampu dikeringkan, kemudian disterilkan dengan menggunakan autoklaf pada suhu $121^{\circ} \mathrm{C}$ selama 15 menit (Ortez, 2005). Laminary air flow yang digunakan untuk pengerjaan disterilkan menggunakan alkohol dan lampu bunsen.

\section{Ekstraksi}

Sampel spons dimaserasi dalam larutan etanol selama 24 jam selanjutnya disaring dengan menggunakan kertas Whattman untuk mendapatkan ekstrak spons. Ekstrak etanol sampel spons kemudian diuapkan dengan Rotary vacuum evaporator pada suhu $40^{\circ}$ hingga kering.

\section{Pembuatan Media}

a. Media cair Brain Heart Infusum (BHI)

Ditimbang sebanyak 37 gram agar $\mathrm{BHI}$ kemudian dilarutkan dengan 1 liter aquades. Media dituang ke dalam tabung reaksi sebanyak $10 \mathrm{ml}$ per tabung. Kemudian disterilkan dengan autoklaf pada suhu $121^{\circ} \mathrm{C}$ selama 15 menit.

\section{b. Media Nutrien Agar (NA)}

Ditimbang sebanyak 23 gram agar nutrien dilarutkan dalam 1 liter aquades. Media dituang ke dalam tabung reaksi sebanyak $10 \mathrm{ml}$ per tabung. Kemudian disterilkan dengan autoklaf pada suhu $121^{\circ} \mathrm{C}$ selama 15 menit.

c. Media Mueller Hinton Agar (MHA) Ditimbang sebanyak 38 gram MHA kemudian dilarutkan dengan 1 liter aquades. Media disterilkan dengan autoklaf pada suhu $121^{\circ} \mathrm{C}$ selama 15 menit. Kemudian media dituang ke dalam cawan petri sebannyak $20 \mathrm{ml}$ per cawan. 


\section{Pembuatan Kontrol Positif dan Kontrol Negatif}

Kontrol positif dibuat dari sediaan kapsul kloramfenikol 250 gram yang dilarutkan dalam $100 \mathrm{ml}$ aquades. Sedangkan kontrol negatif menggunakan cairan etanol $95 \%$.

\section{Kultur Bakteri Uji}

Bakteri uji yang digunakan yaitu Staphylococcus aureus (Gram positif) dan Escherichia coli (Gram negatif). Masing-masing diambil sebanyak 1 ose kemudian digoreskan pada permukaan media NA miring. Selanjutnya media diinkubasi salama 1x24 jam pada suhu $37^{\circ} \mathrm{C}$ (Ortez, 2005).

\section{Aktivitas Antibakteri}

Ada dua metode difusi yang digunakan yaitu metode cakram kertas dan metode sumur. Adanya aktivitas antibakteri ditandai dengan terbentuknya zona bening di sekitar sumur dan cakram. Tahap pengujian awal digunakan metode cakram kertas (disc diffusion Kirby Bauer) yaitu kertas cakram dengan diameter $6 \mathrm{~mm}$ direndam ke dalam larutan spons uji kemudian diletakkan di atas permukaan media MHA lalu diinkubasi selama 1×24 jam pada suhu $37^{\circ} \mathrm{C}$ (Ortez, 2005). Setelah muncul zona bening dilakukan pengujian lanjut dengan menggunakan metode sumur (metode modifikasi Kirby Bauer). Larutan spons uji dievaporasi hingga kering lalu dilarutkan dengan etanol sebanyak $4 \mathrm{ml}$, kemudian dimasukkan ke dalam tiga buah sumur berdiameter $6 \mathrm{~mm}$. Sumur ke empat diisi dengan etanol sebagai kontrol positif dan sumur kelima diisi dengan larutan kloramfenikol sebagai kontrol positif. Selanjutnya media diinkubasi selama 1x24 jam pada suhu $37^{\circ} \mathrm{C}$.

\section{HASIL DAN PEMBAHASAN}

\section{Sampel Spons Dari Perairan Bunaken}

Sampel spons yang diambil dari Tanjung Parigi dan Mamaling sebanyak dua belas sampel dan yang berhasil diidentifikasi sebanyak empat sampel. Sedikitnya sampel yang berhasil diidentifikasi dikarenakan kecilnya ukuran sampel yang diambil.

\section{Hasil Pengujian di Laboratorium Uji Awal}

Pengujian awal dilakukan untuk melihat aktivitas semua sampel terhadap bakteri uji Staphylococcus aureus dan Escherichia coli. Hasil dari pengujian awal menunjukkan bahwa beberapa sampel yang diambil memberikan zona hambat terhadap bakteri uji.

Berdasarkan hasil penapisan awal, dipilih dua spesies spons yang memberikan zona hambat yang besar yaitu Dictyonella funicularis dan Phyllospongia lamellosa (Tabel 1). Kemudian dilakukan pengujian lanjut terhadap dua sampel yang dipilih dengan menggunakan metode sumur.

Tabel 1. Ekstrak spons laut yang mempunyai aktivitas terhadap Staphylococcus aureus dan Eschericia coli

\begin{tabular}{ccc}
\hline Sampel & S. Aureus & E. Coli \\
\hline 1 & - & - \\
2 & - & - \\
Amphimedon & - & - \\
chloros & & \\
4 & + & + \\
5 & + & + \\
6 & + & - \\
Dictyonella & + & + \\
funicularis & + & - \\
8 & - & - \\
9 & + & - \\
10 & + & + \\
Phyllospongia & & \\
lamellosa & + & +- \\
13 & Ketiki aktivitas
\end{tabular}




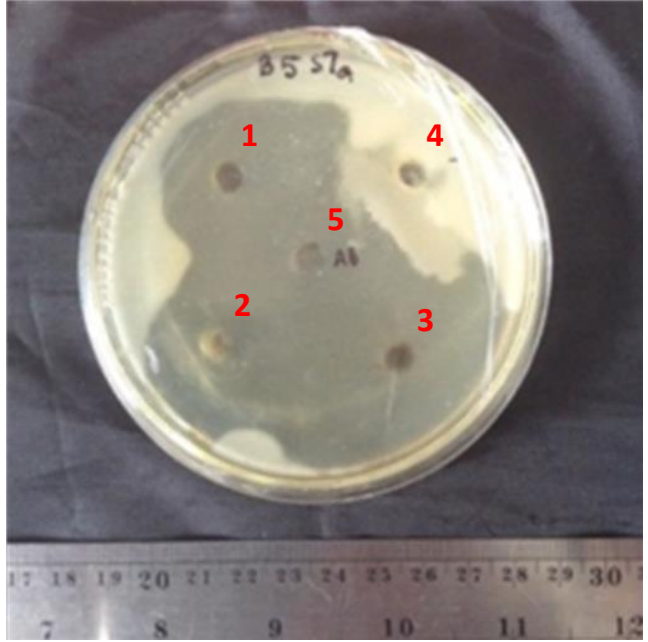

$1 a$

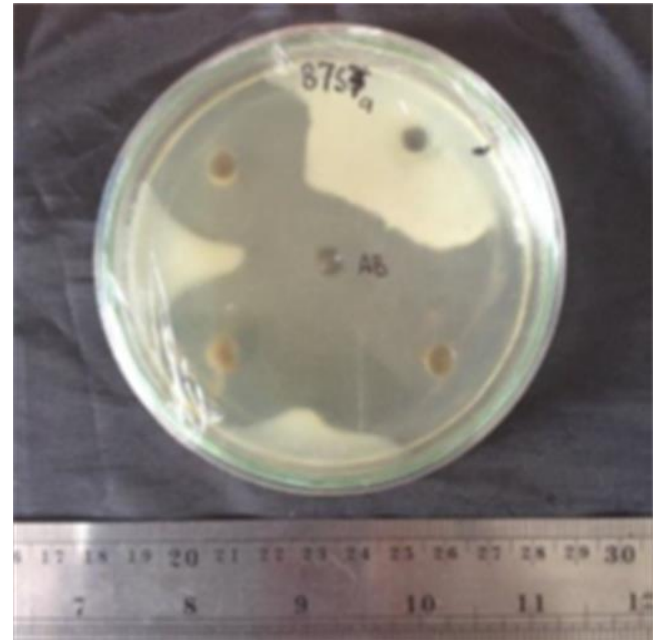

$1 b$

Gambar 1. Zona hambat ekstrak spons Dictyonella funicularis pada pengamatan $1 \times 24$ jam terhadap pertumbuhan bakteri (1a) Staphylococcus aureus dan (1b) Eschericia coli.

Keterangan: 1,2,3 = Ekstrak spons, 4 = Kontrol Negatif, 5 = Kontrol Positif

\section{Pengujian Terhadap Spons Dictyonella funicularis}

Setelah diinkubasi selama $1 \times 24$ jam pada suhu $37^{\circ} \mathrm{C}$, ekstrak Dictyonella funicularis menunjukkan adanya daya hambat terhadap bakteri Staphylococcus aureus dan Escherichia coli (Gambar 1).

Pengamatan dilanjutkan selama 2x24 jam untuk melihat apakah ada perubahan yang terjadi, namun tidak terjadi perubahan yang signifikan terhadap bakteri uji.

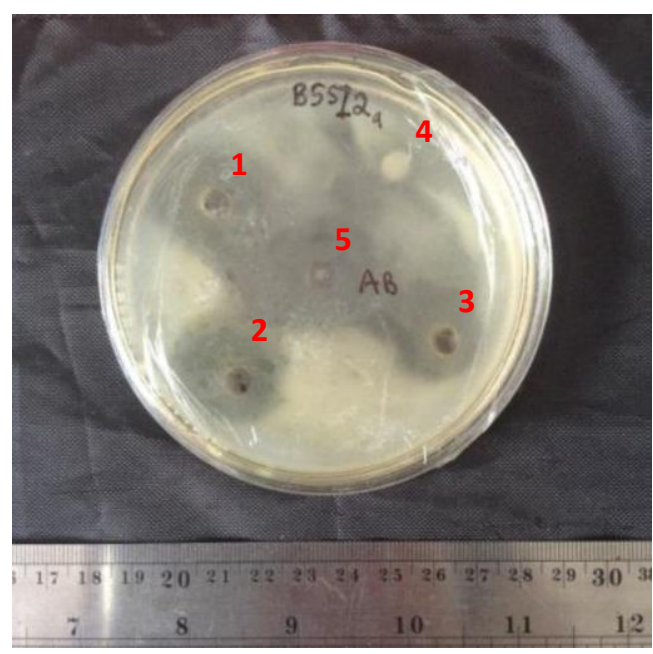

$2 a$

\section{Pengujian Terhadap Spons Phyllospongia lamellosa}

Setelah diinkubasi selama $1 \times 24$ jam pada suhu $37^{\circ} \mathrm{C}$, ekstrak Phyllospongia lamellosa menunjukkan adanya daya hambat terhadap bakteri Staphylococcus aureus dan Escherichia coli (Gambar 2).

Pengamatan dilanjutkan selama 2x24 jam untuk melihat apakah ada perubahan yang terjadi, namun tidak terjadi perubahan yang signifikan terhadap bakteri uji.

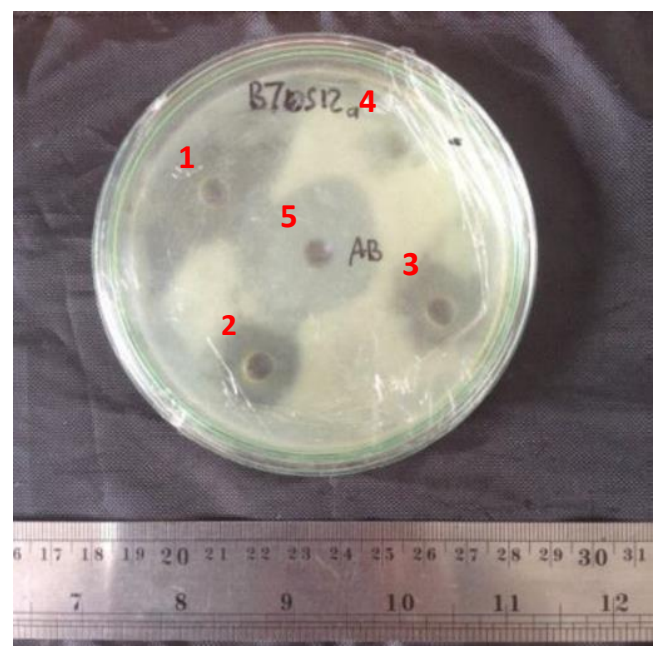

$2 b$

Gambar 2. Zona hambat ekstrak spons Phyllospongia lamellosa pada pengamatan 1x24 jam terhadap pertumbuhan bakteri (2a) Staphylococcus aureus dan (2b) Eschericia coli.

Keterangan: $1,2,3=$ Ekstrak spons, $4=$ Kontrol Negatif, $5=$ Kontrol Positif 
Tabel 2. Rerata diameter zona hambat ekstrak spons Dictyonella funicularis dan Phyllospongia lamellosa pada pertumbuhan bakteri Staphylococcus aureus dan Eschericia coli.

\begin{tabular}{ccc}
\hline \multirow{2}{*}{$\begin{array}{c}\text { Spesies } \\
\text { Spons/Antibiotik }\end{array}$} & \multicolumn{2}{c}{ Bakteri } \\
\cline { 2 - 3 }$(\mathrm{mm})$ & $\begin{array}{c}\text { E.coli } \\
(\mathrm{mm})\end{array}$ \\
\hline $\begin{array}{c}\text { Dictyonella } \\
\text { funicularis } \\
\text { Phyllospongia } \\
\text { lamellosa }\end{array}$ & $38,83 \pm 6,59$ & $42,33 \pm 3,08$ \\
Antibiotik & $18,00 \pm 6,26$ & $25,17 \pm 5,34$ \\
\hline
\end{tabular}

Keterangan $\pm=$ Standart deviasi

Berdasarkan hasil penelitian, terlihat bahwa kedua ekstrak menunjukkan adanya aktivitas antibakteri terhadap bakteri uji Staphylococcus aureus dan Eschericia coli. Hasil pengukuran rerata diameter zona hambat ekstrak spons uji dan antibiotik disalin dalam tabel 2 .

Penelitian ini memperlihatkan bahwa ekstrak spons Dictyonella funicularis dan Phyllospongia lamellosa memiliki daya hambat terhadap kedua bakteri uji. Namun ekstrak spons Dictyonella funicularis memiliki aktivitas antibakteri yang lebih kuat dibandingkan ekstrak spons Phyllospongia lamellosa. $\mathrm{Hal}$ ini ditunjukkan dengan adanya perbedaan daya hambat yang muncul.

Kedua ekstrak spons menunjukkan adanya aktivitas yang lebih kuat terhadap bakteri Escherichia coli. Sejauh ini pengendalian infeksi Gram negatif seringkali menjadi kendali dalam dunia kedokteran modern, hal ini diakibatkan oleh karakteristik bakteri kelompok Gram negatif memiliki dinding peptidoglikan yang cukup padat dan kompak serta adanya "efflux-pump mechanism" yaitu suatu mekanisme untuk mengeluarakn sanyawa-senyawa yang tidak dibutuhkan dalam prosesproses biotransformasi seluler bakteri melalui sistem sekresi, sehingga menghambat proses internalisasi senyawa untuk mampu mempengaruhi mekanisme selular dari bakteri (Poole,
2007; Posangi et al., 2014; Bara et al., 2015).

Kekuatan senyawa bioaktif yang terkandung dalam ekstrak spons laut dapat dilihat dengan menggunakan lebar diameter zona hambat sebagai parameternya. Semakin lebar diameter zona hambat yang terbentuk menandakan semakin kuatnya senyawa bioaktif tersebut menghambat pertumbuhan bakteri.

Dalam penelitian ini, ekstrak Dictyonella funicularis memiliki senyawa antibakteri yang cukup kuat. Selanjutnya peneliti melakukan pencarian mengenai penelitian serupa dengan mesin pencari pada situs www.Google.scholar.com, untuk dibandingkan dengan penelitian ini namun tidak ditemukan adanya penelitian tentang aktivitas antibakteri dari spesies yang sama. Penelitian oleh Konuklugil dan Gozcelioglu (2015) juga dilakukan terhadap genus Dictyonella namun dari spesies yang berbeda yaitu Dictyonella incisa yang tumbuh di Perairan Turki. Pada penelitian tersebut ekstrak Dictyonella incisa menunjukkan adanya aktifitas antibakteri terhadap bakteri Staphylococcus aureus.

Ekstrak lainnya dari spons Phyllospongia lamellosa juga dipastikan memiliki senyawa antibakteri. Penelitian oleh Undap (2016) dan Dajoh (2004) menunjukkan adanya senyawa dari Phyllospongia lamellosa yang dapat menghambat pertumbuhan bakteri. Penelitian tersebut serupa dengan penelitian ini yaitu tentang spesies Phyllospongia lamellosa yang diambil dari Perairan Bunaken yang juga memiliki kandungan senyawa antibakteri.Dibandingkan dengan antibiotik pembanding, diameter zona hambat yang terbentuk di sekitar ekstrak Dictyonella funicularis lebih besar. Hal ini menunjukan aktivitas antibakteri yang sangat tinggi pada bakteri uji Esherichia coli dan Staphylococcus aureus. Sehingga spesies ini dapat dikembangkan karena memiliki potensi sebagai obat antibakteri. Ekstrak Phyllospongia 
lamellosa juga menunjukkan aktivitas antibakteri moderat terhadap bakteri uji Eschericia coli dan Staphylococcus aureus, walaupun aktivitasnya masih sedikit lebih rendah dibandingkan dengan antibiotik pembanding.

Pengamatan dilanjutkan selama 2x24 jam dilakukan untuk melihat sifat dari ekstrak spons yang diuji, apakah bersifat bakteristatik, bakterisidal, atau bakterilitik. Hasil yang diperlihatkan oleh kedua ekstrak spons uji bahwa zona bening yang terbentuk tidak jauh berbeda dengan pengamatan 1x24 jam. Hal ini berartri ekstrak spons yang diuji bersifat bakterisidal yaitu membunuh bakteri, tidak hanya mencegah mereka berkembang biak.

\section{KESIMPULAN}

Berdasarkan hasil penelitian dapat disimpulkan bahwa ekstrak Dictyonella funicularis dan Phyllospongia lamellosa mempunyai aktivitas terhadap bakteri Staphylococcus aureus dan Eschericia coli.

\section{DAFTAR PUSTAKA}

Abubakar, H., Wahyudi, A.T., Yuhana, M. 2011. Skrining Bakteri yang Berasosiasi dengan Spons Jaspis sp. Sebagai Penghasil Senyawa Antimikroba. Jurnal IImu Kelautan. VOL. 16 (1). Hal. 35-40.

Badan Informasi Geospasial. 2015. Diakses pada 12 Mei 2016 dari https://www.bakosurtanal.go.id.

Bara, R. A., Kandou, G., Ola, A., Posangi, J. 2015. Analisis Senyawa Antibiotik Dari Jamur Simbion Yang Terdapat Dalam Ascidians Didemnum molle $\mathrm{Di}$ Sekitar Perairan Bunaken Sulawesi Utara. Jurnal LPPM Bidang Sains dan Teknologi. VOL. 2(2).
Dajoh, O. 2004. Pengujian Aktifitas Antibakteri dari Spons di Perairan Selat Lembeh. Manado: Skripsi FPIK UNSRAT.

Denning, D. 2006. Branches on the Tree of Life: Sponges. from http://ebiomedia.com/prod/BOspo nges.html.

Konuklugil, B., Gozcelioglu, B. 2015. Antimicrobial Activity of Marine Samples Collected From The Different Coasts of Turkey. Turkish Journal of Pharmaceutical Sciences. 12(3) : 337-344.

Mokodompit, A., Boekoesoe, L., Mustapa, M. A. 2015. Uji Aktifitas Antibakteri Ekstrak Etanol Spons Laut (Porifera: Demospongiae) Terhadap Bakteri Staphylococcus aureus dan Escherchia coli. Gorontalo: Universitas Negeri Gorontalo.

Nybakken, J. W. 1988. Biologi Laut: Suatu Pendekatan Ekologis. Jakarta: Gramedia. 459 halaman.

Ortez, J. 2005. Disk Diffusion Testing in Manual of Antimicrobial Susceptibility testing. Marie B. Coyle (Coord. Ed). American society for Microbiology.

Poole, K. (2007). Efflux pumps as antimicrobial resistance mechanisms. Annals of Medicine 39(3): 162-176.

Posangi, J., Bara, R. A. 2014. Analisis Aktivitas Dari Jamur Endofit Yang Terdapat Dalam Tumbuhan Bakau Avicennia marina di Tasik Ria Minahasa. Jurnal Pesisir dan Laut Tropis. VOL. 1(1).

Suparno. 2005. Kajian Bioaktif spons laut (Porifera: Demospongiae) Suatu Peluang Alternative Pemanfaatan Ekosistem Karang Indonesia Dalam Bidang Farmasi. 
Makalah Pribadi. Bogor: Institute Pertanian Bogor.

Undap, N. 2016. Senyawa antibakteri spons Smenospongia aurea, Strepsichordaia sp., Agelas tubulata dan Phyllospongia sp., dari perairan pantai Malalayang Manado terhadap pertumbuhan strain bakteri. Tessis. Manado: Pasca Sarjana Universitas Sam Ratulangi. 